\title{
Torque teno (TTV) viral load as a biomarker of immunosuppressive strength after kidney transplantation in children
}

\author{
Ryszard Grenda ${ }^{1}$ (D)
}

Received: 4 May 2020 / Accepted: 8 May 2020 / Published online: 27 May 2020

(C) IPNA 2020

$\begin{array}{ll}\text { Abbreviations } \\ \text { TTV } & \text { Torque teno virus } \\ \text { TDM } & \text { Therapeutic drug monitoring } \\ \text { AUC } & \text { Area under curve } \\ \text { TAC } & \text { Tacrolimus } \\ \text { CsA } & \text { Cyclosporine A } \\ \text { MMF } & \text { Mycophenolate mofetil } \\ \text { SIR } & \text { Sirolimus } \\ \text { DSA } & \text { Donor-specific antibodies } \\ \text { CMV } & \text { Cytomegalovirus } \\ \text { EBV } & \text { Epstein-Barr virus } \\ \text { mTORi } & \text { Mammalian target of rapamycin kinase inhibitor } \\ \text { CNI } & \text { Calcineurine inhibitor } \\ \text { MPA } & \text { Mycophenolic acid }\end{array}$

\section{Introduction}

There is an ongoing clinical conflict of interest between the risk of rejection and over-immunosuppression in patients after organ transplantation, therefore effective monitoring of the strength of immunosuppressive therapy is crucial for optimal care. Routinely, the monitoring is conducted in several forms, including ongoing clinical alert of symptoms and causes of graft dysfunction (rejection/nephrotoxicity/infection), awareness of drug-specific or universal (infection/malignancies) adverse events, therapeutic drug monitoring (TDM) for maintenance immunosuppressives, and/or evaluating the count of cells presenting specific surface receptors, targeted by biologic drugs. Optimal drug concentration is variable, depending on timing after transplantation, drug combination (different for

Ryszard Grenda

r.grenda@ipczd.pl

1 Department of Nephrology, Kidney Transplantation \& Hypertension, The Children's Memorial Health Institute, Warsaw, Poland
$\mathrm{TAC}+\mathrm{MMF}, \mathrm{CsA}+\mathrm{MMF}, \mathrm{CsA}+\mathrm{SIR})$, and individual (age-related and/or gene-dependent) pharmacodynamics/ pharmacokinetics. There are ongoing attempts to define other specific biomarkers, feasible for monitoring the immunological status of the recipient, mainly focused on early detection of humoral rejection and monitoring of donor-specific antibodies (DSA). Nevertheless, the progress in this term, looking for other feasible and effective monitoring tests, is an ongoing challenge [1-5].

\section{Torque teno virus and transplantation-related issues}

Torque teno virus (TTV), discovered in 1977, has recently gained a lot of interest as a potential biomarker of immune status in humans. It is a member of the Anellovirus family, with (so far) 29 genotypes, present in the majority of healthy non-symptomatic individuals. TTV is present in several body tissues and cells (except erythrocytes and platelets) and replicates in the bone marrow, liver, and T-lymphocytes. Over $90 \%$ of the TTV pool is cleared by the immune system, and the viral load reflects this process. Replication of TTV is correlated with the number and function of $\mathrm{T}$ cells, with genetic variations of co-stimulatory molecule T-lymphocyte antigen 4 (CTLA-4) and with the administration of immunosuppression [6-8]. In adult kidney recipients, baseline TTV viral load has increased between first and fourth week post-transplant, reached a peak between 3 and 12 months, and then gradually decreased beyond 1 year [9]. The viral load of TTV was higher in patients co-infected with EBV and CMV. TTV viral load is increased in patients with primary CMV infection compared with patients with latent CMV infection or reactivation. Interestingly, anti-CMV prophylaxis has no effect on TTV viral load, however high TTV load was predictive for subsequent CMV reactivation $[10,11]$. Overall, with more potent immunosuppressive drugs/drug combinations used after kidney transplantation, the TTV viral load was higher, however this association was related to dose (or fact of using), rather 
than to blood concentration. Exclusively, the use of mTORi was associated with lower viral load. Higher viral load is caused by (drug-mediated) reduced ability of T cells to control the proliferation of TTV [6]. This mechanism may additionally be modified by the use of biologic antibodies (mono- or polyclonal) in induction. Biologics exert a distinct effect on $\mathrm{T}$ cells (blocking or depleting), and the duration of this effect is variable (approx. 2 months for 2 doses of basiliximab vs up to 12 months with full dose of thymoglobulin, and variably shorter with different lower cumulative doses). Basiliximab, as a non-depleting agent, causes lower reduction of TTV load than polyclonal induction [12]. Therefore, probably immunosuppressive regimen-specific thresholds of TTV viral loads, predictive for infection/SAE/rejection should be defined.

\section{Add-on approach using torque teno viral load as surveillance biomarker in renal transplantation}

There is ongoing interest in terms of the suitability of monitoring TTV load as a biomarker of the strength of different immunosuppressive regimens in recipients of solid organs, including the liver, lungs, and kidney; however, direct extrapolating of reported results from one type of organ transplantation to another must be cautious. Studies in adult kidney recipients enrolled patients on variable immunosuppression. Most cases received triple regimen (CNI/MMF/Pred), however the use of both types of induction, mTORi and belatacept, was also allowed. In one study, infected patients showed significantly higher TTV levels compared with patients without infection $\left(4.2 \times 10^{8} \mathrm{copies} / P=0.006\right)$. Each $\log$ level of TTV copies $/ \mathrm{mL}$ increased the odds ratio for infection by $23 \%(P=0.014)$. Viral load of TTV $>3.1 \times 10^{9}$ copies $/ \mathrm{mL}$ corresponded to $90 \%$ sensitivity to predict infections [11]. Another study compared 33 patients with biopsy-proven acute rejection with 80 stable patients. The risk for alloreactivity decreased by $10 \%$ per log level of TTV copies $/ \mathrm{mL}(P=0.005)$ [13]. Value of TTV load at 3-month post-transplant was analyzed in the context of subsequent biopsy-proven rejection and infection within the first year post-transplantation. Each log increase in TTV load decreased the odds for rejection by $22 \%(P=0.027)$ and increased the odds for infection by $11 \%(P<0.001)$. TTV load between $1 \times 10^{6}$ and $1 \times 10^{8}$ copies $/ \mathrm{mL}$ was suggested to be optimal to minimize the risk of rejection and infection [14]. Viral load above $3.15 \times 10^{10}$ copies was predictive for infection while $4.56 \times 10^{10}$ for immunosuppression-related adverse events, in another trial [9].

\section{Study in pediatric kidney transplantation}

The current study reported by Uhl et al. [15] is the first published pediatric trial in a setting of kidney transplantation, including (finally) 45 patients completing all criteria and followed up to 1 year after transplantation. None received induction, however they were on variable maintenance immunosuppression (39 on triple, 6 on dual protocol, including 39 on TAC, 3 on CsA, 3 on SIR, 35 on MMF, and 4 on AZA; all on steroids). Variable viral load (from 2.34 to $10 \times 10^{10}$ copies $/ \mathrm{mL}$; median $5.8 \log _{10}$ ) was detected, and younger children $(<5$ years of age) showed higher values. Overall, revealed correlations and trends were similar to adult data: triple regimen showed a trend to be more potent (in terms of higher viral load) compared with dual; mTORi (SIR)-treated patients had lower (about nearly $2 \log _{10}$ ) viral load than those receiving CNIs; no correlation was found with drug concentration; however, there was a significant correlation with dose of MMF and steroids, and there was a trend (in correlation) with doses of TAC and SIR. There was no correlation between TTV loads with production of DSA. As no patients demonstrated rejection, analysis of this correlation (with TTV load) was not possible.

\section{Unanswered questions in kidney transplantation}

- Is pre-transplant mismatch in terms of TTV transmission (donor positive/recipient negative) important for further monitoring of viral load?

- Are younger children at higher risk of such transmission (as for EBV)?

- Which of the maintenance drugs used in combination (triple) protocol (beyond mTORi) is more significant for final (combined?) effect on TTV load?

- Is the dynamics of TTV load more important for optimal tailoring of the treatment, than traditional TDM?

- Is TTV load reliable for decreasing the doses of maintenance drugs in patients given long-acting depleting induction?

- When the dynamics of TTV viral load "predicts" further infection in a stable patient, should we pre-emptively decrease immunosuppression, introduce some antiinfectious prophylaxis, or just wait and enhance routine surveillance?

\section{Conclusion}

Monitoring of TTV load and dynamics has the potential to improve the long-term care in pediatric renal transplantation, however the variety of confounding factors currently make final conclusions disputable. It is not clear whether the optimal threshold of TTV load is individual for specific drug combinations. Carefully designed controlled trials are required to 
find more evidence, however the enrolled patients should receive simplified immunosuppressive (triple) protocols to avoid the ambiguity caused by conflicting effects of different drugs on TTV proliferation and systemic clearance, and therefore on its predictive value for under- or overimmunosuppression.

\section{Compliance with ethical standards}

Conflict of interest The author declares that he has no conflict of interest.

\section{References}

1. Weber LT (2015) Therapeutic drug monitoring in pediatric renal transplantation. Pediatr Nephrol 30:253-265

2. Larkins N, Matsell DG (2014) Tacrolimus therapeutic drug monitoring and pediatric renal transplant graft outcomes. Pediatr Transplant 18:803-809

3. Grenda R (2015) Biologics in renal transplantation. Pediatr Nephrol 30:1087-1098

4. Engen RM, Park GE, Schumacher CS, Gimferrer I, Warner P, Finn LS, Weiss NS, Smith JM (2018) Donor-specific antibody surveillance and graft outcomes in pediatric kidney transplant recipients. Transplantation 102:2072-2079

5. Faddoul G, Nadkarni GN, Bridges ND, Goebel J, Hricik DE, Formica R, Menon MC, Morrison Y, Murphy B, Newell K, Nickerson P, Poggio ED, Rush D, Heeger PS, CTOT-17 consortium (2018) Analysis of biomarkers within the initial 2 years posttransplant and 5-year kidney transplant outcomes: results from clinical trials in organ transplantation-17. Transplantation 102:673680

6. Rezahosseini O, Drabe C, Sørensen S, Rasmussen A, Perch M, Ostrowski S, Nielsen S (2019) Torque-teno virus viral load as a potential endogenous marker of immune function in solid organ transplantation. Transplant Rev (Orlando) 33:137-144

7. Focosi D, Antonelli G, Pistello M, Maggi F (2016) Torquetenovirus: the human virome from bench to bedside. Clin Microbiol Infect 22:589-593
8. Bostan N, Nabgh E, Bokhari H (2013) Current and future prospects of torque teno virus. J Vaccines Vaccin 4:S1-S4

9. Fernandez-Ruiz M, Albert E, Gimenez E, Ruiz-Merlo T, Parra P, Lopez-Medrano F, San Juan R, Polanco N, Andres A, Navarro D, Aguado J (2019) Monitoring of alphatorquevirus DNA levels for the prediction of immunosuppression-related complications after kidney transplantation. Am J Transplant 19:1139-1149

10. Borkosky S, Whitley C, Kopp-Schneider A, Zur Hausen H, de Villiers E (2012) Epstein-Barr virus stimulates torque teno virus replication; a possible relationship to mulitiple sclerosis. PLoS One 7:e32160

11. Strassl R, Schiemann M, Doberer K, Görzer I, Puchhammer-Stöckl E, Eskandary F, Kikic Ž, Gualdoni GA, Vossen MG, RasoulRockenschaub S, Herkner H, Böhmig GA, Bond G (2018) Quantification of torque teno virus viremia as a prospective biomarker for infectious disease in kidney allograft recipients. J Infect Dis 218:1191-1199

12. Focosi D, Macera L, Boggi U, Nelli L, Maggi F (2015) Short term kinetics of torque teno virus viremia after induction immunosuppression confirms $\mathrm{T}$ lymphocytes as main replication-competent cells. J Gen Virol 96:115-117

13. Strassl R, Doberer K, Rasoul-Rockenschaub S, Herkner H, Görzer I, Kläger JP, Schmidt R, Haslacher H, Schiemann M, Eskandary FA, Kikić Ž, Reindl-Schwaighofer R, Puchhammer-Stöckl E, Böhmig GA, Bond G (2019) Torque teno virus for risk stratification of acute biopsy-proven alloreactivity in kidney transplant recipients. J Infect Dis 219:1934-1939

14. Doberer K, Schiemann M, Strassl R, Haupenthal F, Dermuth F, Görzer I, Eskandary F, Reindl-Schwaighofer R, Kikić Ž, Puchhammer-Stöckl E, Böhmig GA, Bond G (2020) Torque teno virus for risk stratification of graft rejection and infection in kidney transplant recipients - a prospective observational trial. Am J Transplant. https://doi.org/10.1111/ajt.15810

15. Uhl P, Heilos A, Bond G, Meyer E, Böhm M, Puchhammer-Stöckl E, Arbeiter K, Müller-Sacherer T, Csaicsich D, Aufricht C, Rusai K (2020) Torque Teno viral load reflects immunosuppression in paediatric kidney transplanted patient - a pilot study. Pediatr Nephrol

Publisher's note Springer Nature remains neutral with regard to jurisdictional claims in published maps and institutional affiliations. 